\title{
Effects of cryogenic treatment on residual stresses of AISI D2 tool steel
}

\author{
E. Demir*, İ. Toktaş \\ Mechanical Engineering Department, Ankara Yıldırım Beyazıt University, Ankara 06010, Turkey
}

Received 27 November 2017, received in revised form 22 May 2018, accepted 25 May 2018

\begin{abstract}
Positive effects of cryogenic treatment on residual stresses of AISI D2 cold work tool steel were studied in this article. Samples were exposed to the cryogenic treatment at $-145^{\circ} \mathrm{C}$ for short and long holding durations ( 4 and $24 \mathrm{~h}$, respectively). Alteration in residual stress distribution was correlated with the microstructure, hardness and surface roughness examinations of the samples. Results showed that cryogenic treatment reduced the residual surface stresses in comparison to the conventional heat treatment. There was no significant difference in hardness values and retained austenite contents. However, more dense and homogeneous carbide precipitation was observed mainly for the cryo-treated sample for $24 \mathrm{~h}$. Surface roughness was found better for cryo-treated samples. In general, holding duration of $24 \mathrm{~h}$ represented preferable conditions, and this case was achieved by using the improved microstructure.
\end{abstract}

K e y wo r d s: AISI D2 steel, cryogenic treatment, residual stress, carbide precipitation, surface roughness

\section{Introduction}

Residual stresses remain within the material when stress causing factors like heat change and external forces are removed. Residual stresses occur due to irregular plastic deformations, welding, grinding, phase and heat treatment transformations. Taking the residual stresses in steels into account is quite significant for particle design, and this provides an improvement not only in fatigue strength but also in dimensional stability of the materials [1].

AISI D2 is a cold work tool steel commonly used in many industrial applications such as cutting, punching, stamping tools and shear blades. It has high resistance to abrasive and adhesive wear mechanisms due to a high carbide content, improved toughness, high dimensional stability and compressive strength. Also, the cold work tool steels are subjected to impact effects in cutting, punching and stamping processes. Therefore, internal (residual) stresses have to be minimized. Research works conducted in the last two decades have stated that the service life of tool/die steels can be immensely enhanced by applying cryogenic treatment after conventional heat treatment [2]. The material is cooled down to sub-zero temperatures and is held at this temperature for a certain period, then the temperature is turned back to room temperature. This process is called as cryogenic treatment. Cryogenic treatment aims to get the desired mechanical properties by making permanent changes in the microstructure of the material with minimum negative effects [3]. Conventional heat treatment results in retained austenite in the material. As retained austenite is a soft phase, it is an undesired structure and negatively affects wear resistance and toughness of materials $[4,5]$. Austenite to martensite transformation temperature of AISI D2 steel subjected to this study can be accepted around $-125^{\circ} \mathrm{C}[6]$.

Alexandru and Bulancea [7] claimed that in addition to the transformation of austenite to martensite, cryogenic treatment causes the following effects: (i) appropriate redistribution of carbide phases of alloy 
elements, (ii) precipitation of alloy carbide elements with very small sizes (smaller than $1 \mu \mathrm{m}$ ), and (iii) appropriate redistribution of residual stresses.

Two theories were considered for an explanation of the secondary carbide formation during cryogenic treatment and tempering processes. One of them is based on the carbon atom jumping [8] while the other one matches with the carbon atoms catching in the dislocation areas [9]. As long as temperature reduces during cryogenic treatment, the carbon atoms in the martensite matrix are forced to jump to nearby defects such as grain boundaries and dislocation gaps due to structure contraction. Hence, carbide density increases and they are redistributed during the tempering process. Jumping theory is more common than trapping theory for explaining the carbide formation [10].

Collins and Dormer [11] and Surberg et al. [12] searched for the effect of austenitizing temperature on the microstructure of AISI D2 steel. As austenitizing temperature increases, the hardness difference between conventional heat treatment and deep cryogenic treatment increases. Rhyim et al. [13] analysed the effects of tempering temperature on hardness and microstructure of AISI D2 tool steel subjected to conventional heat treatment, cold treatment and deep cryogenic treatment. They found that the increment in tempering temperature decreased the hardness of AISI D2 steel. The effects of sub-zero treatments in wear resistance of AISI D2 tool steel have been studied widely. Wear resistance improved by cryogenic treatment declined the amount of retained austenite and improved the secondary carbide precipitation $[2,14-$ 16]. Das et al. [17] and Oppenkowski et al. [18] suggested that $36 \mathrm{~h}$ holding time at $-196^{\circ} \mathrm{C}$ was optimum duration for wear resistance of AISI D2 tool steel.

Bensely et al. [19] examined the effects of shallow cryogenic treatment $\left(-80^{\circ} \mathrm{C}, 5 \mathrm{~h}\right)$ and deep cryogenic treatment $\left(-196^{\circ} \mathrm{C}, 24 \mathrm{~h}\right)$ on residual stresses of En 353 steel. Results showed that tempering after deep cryogenic treatment decreased the residual stresses. Reduction in residual stresses was associated with high amount of fine carbide precipitation. Under the same cryogenic temperatures and holding durations used by Bensely et al. [19], conventional heat treatment and shallow cryogenic treatment led to tensile residual stress while deep cryogenic treatment generated compressive residual stress in 4140 steel [1].

Paydar et al. [20] applied cryogenic treatment to $100 \mathrm{Cr} 6$ alloy steel for $24 \mathrm{~h}$ and found that wear resistance and hardness were improved by more uniform carbide precipitation and retained austenite elimination. Amini et al. [21] investigated the effect of cryogenic treatment for long holding periods as 24, 36, $48,72,96$ and $120 \mathrm{~h}$ on corrosion behaviour of 1.2080 tool. Corrosion resistance was reduced by $54 \%$ for $24 \mathrm{~h}$ and continued to decrease up to $36 \mathrm{~h}$. Longer holding
Table 1. The chemical composition of AISI D2 steel (wt.\%)

\begin{tabular}{cccccccc}
\hline Elements & $\mathrm{C}$ & $\mathrm{Mn}$ & $\mathrm{Cr}$ & $\mathrm{Si}$ & $\mathrm{Mo}$ & $\mathrm{V}$ & $\mathrm{Fe}$ \\
\hline Amount & 1.55 & 0.4 & 11.3 & 0.3 & 0.8 & 0.8 & Balance \\
\hline
\end{tabular}

times than $36 \mathrm{~h}$ did not represent any difference and this result was correlated to the dissolved chromium elements playing an important role in corrosion resistance. In another study [22], welded joints were subjected to the cryogenic treatment for 2, 15, 24 and $48 \mathrm{~h}$ and residual stresses in the welding region were reduced most at $24 \mathrm{~h}$ holding time.

There are some studies in the literature examining the effects of cryogenic treatment on different mechanical properties of the materials. The unique importance of this study is to examine the effects of deep cryogenic treatment $\left(-145^{\circ} \mathrm{C}\right)$ in short $(4 \mathrm{~h})$ and long ( $24 \mathrm{~h})$ holding times on residual stresses of AISI D2 cold work tool steel. Microstructure, hardness and surface roughness characterization were also examined, and correlations of them were evaluated.

\section{Experimental studies}

\subsection{Materials and heat treatments}

In this study, AISI D2 cold work tool steel was selected as the test material, and its chemical composition is given in Table 1. AISI D2 cold work tool steel bars with a diameter of $20 \mathrm{~mm}$ and length of $50 \mathrm{~mm}$ were subjected to conventional heat treatment (CHT) and deep cryogenic treatment (DCT). Firstly, all of the samples were preheated at $850^{\circ} \mathrm{C}$ for $20 \mathrm{~min}$ and austenitized at $1030^{\circ} \mathrm{C}$ for $30 \mathrm{~min}$. After austenitization process, samples were left for quenching in vacuum furnace under pressurized nitrogen (3 bar). Some of the samples were cooled down gradually from room temperature to $-145^{\circ} \mathrm{C}$ at a cooling rate of $1.5^{\circ} \mathrm{C} \mathrm{min}{ }^{-1}$ and held at this temperature for 4 and $24 \mathrm{~h}$. After that, samples were removed from the cooling furnace and exposed to room temperature. Cryotreated samples are denoted as DCT-4 and DCT-24 by 4 and $24 \mathrm{~h}$ of holding durations at cryogenic temperature. Finally, all samples were tempered at $525^{\circ} \mathrm{C}$ for $2 \mathrm{~h}$ and quenched in the air. Schematic presentations of both CHT and DCT are given in Fig. 1.

For microscopic observations, AISI D2 steel surfaces were ground, polished and etched with $2 \%$ nital. Microstructure images of the samples were taken with an optical microscope (Nikon, Japan). Rockwell hardness values were measured under loading of $150 \mathrm{~kg}$ from 10 different points by using macro hard- 
Table 2. XRD analysis parameters used to examine the samples

\begin{tabular}{lc}
\hline Radiation & $\mathrm{Cr}-\mathrm{K} \alpha$ \\
Poisson's ratio, $\nu$ & 0.28 \\
Young's modulus, $E$ & $211 \mathrm{GPa}$ \\
Diffraction angle, $\theta$ & $156.1^{\circ}$ \\
Lattice planes, $h k l$ & 211 \\
\hline
\end{tabular}

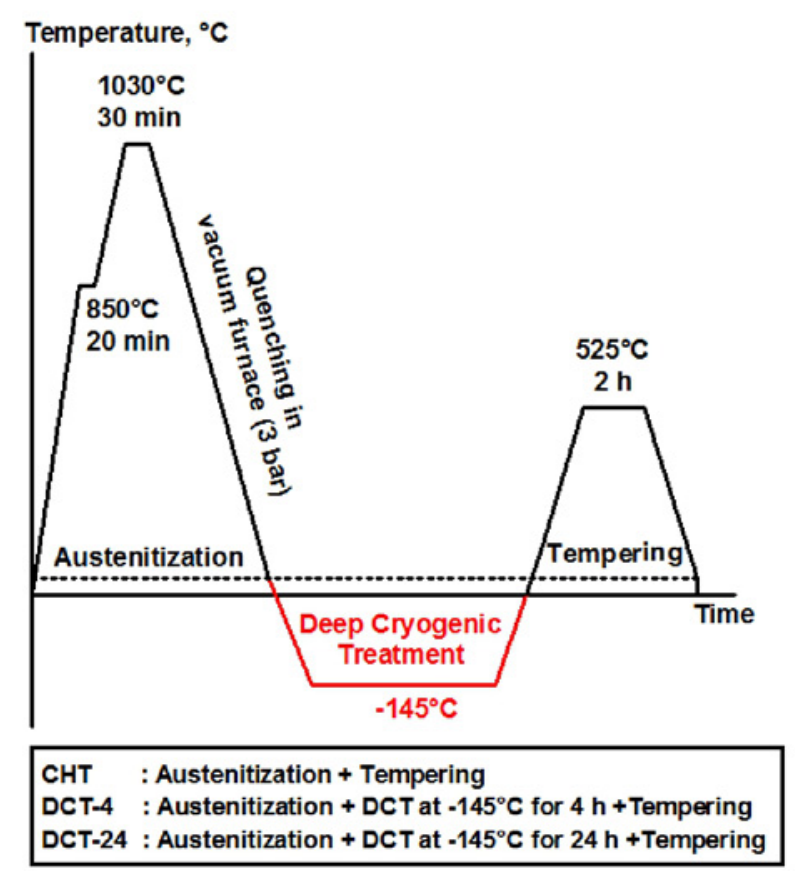

Fig.1. Three different heat treatment procedures applied to samples.

ness tester (Q-ness, Austria). The final hardness value was obtained by taking their mean values. For the surface roughness examinations, all samples were ground at the same grinding parameters. During the grinding process, boron oil and water-based cutting fluid were used for cooling and lubrication purposes. Surface roughness measurements were performed by using surface roughness tester (SJ-301 Mitutoyo, Japan). Average surface roughness value $(R a)$ was determined by taking the mean value of four different measurements.

Surface residual stresses were measured by using $\mathrm{X}$-ray diffraction (XRD) system (GE/Seifert). The data was obtained in several $\Psi$ angles (in range of $-45^{\circ}$ and $45^{\circ}$ ). Measurement parameters used for XRD are given in Table 2. XRD method can measure the residual stresses on sample surfaces. However, there is a need for additional operation of electropolishing before the residual stress measurements deep pro-

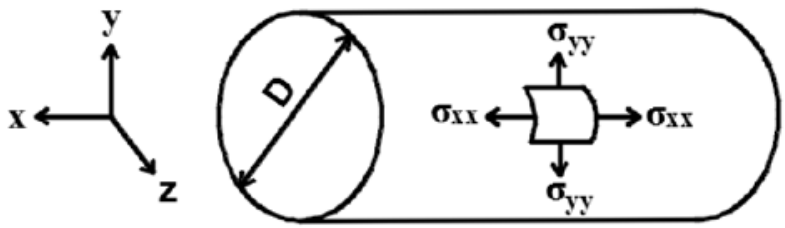

Fig. 2. Stress components measured on the surface and subsurface of the samples.

file by XRD method. Hence, the subsurface stresses were determined by an advanced hole drilling system (Stresstech Prism, Finland) which is based on Electronic Speckle Pattern Interferometer (ESPI) technique. This system is faster than strain gages method, and it is more appropriate for various materials. Furthermore, it gives detailed information about deformations created as a result of hole drilling [23].

AISI D2 tool steel is exposed to the impact loads during cutting, punching and stamping processes. Considering the imposed loads during service conditions of this tool steel, stresses in axial $(x)$ and tangential $(y)$ directions have high importance (Fig. 2). Therefore, stress components along $x$ - and $y$-axes were measured up to $0.5 \mathrm{~mm}$ depth profile of the sample. In the drilling process, TiN coated tungsten carbide drills with a nominal diameter of $0.8 \mathrm{~mm}$ were used.

\section{Results}

\subsection{Microstructural characteristics}

The volume fraction of retained austenite (RA) was analysed by XRD (GE/Seifert) and reported that all the samples contained $<2$ vol. $\%$ of RA. It was not observed any significant difference in RA content for the conventionally treated and cryo-treated samples. Microstructure images with different magnifications were taken with optical microscopy to examine the relative amount and distribution of carbides. As a result of phase analysis with XRD, carbide type in the microstructure was determined as chrome carbides $\left(\mathrm{Cr}_{7} \mathrm{C}_{3}\right.$ and $\left.\mathrm{Cr}_{23} \mathrm{C}_{6}\right)$. Carbides are categorized as primary $(>5 \mu \mathrm{m})$ and secondary $(\leq 5 \mu \mathrm{m})$ concerning their sizes $[2,24]$. Carbide sizes were measured on the microstructure images by using the dimension tools of the optical microscope. Areas marked in Figure 3a and $3 \mathrm{c}$ indicate the primary and secondary carbides.

Primary carbide distribution seems identical for both CHT and DCT samples since the formation of the primary carbides such as the amount, size or distribution depend on the temperature and holding time of the austenitization process [24]. During cryogenic treatment the volume of martensite represents shrinkage, and its lattice parameters also drop off, thereby 

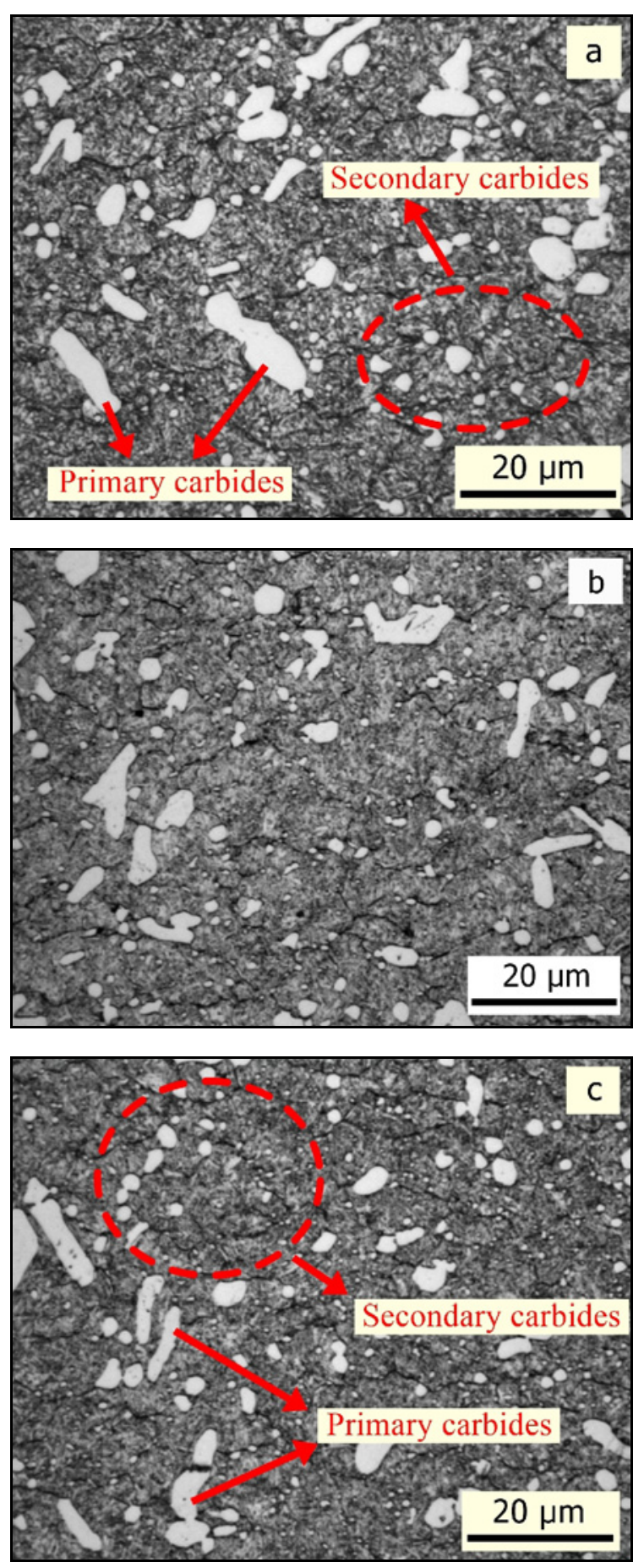

Fig. 3. The microstructure of samples in large-scale CHT (a), DCT-4 (b), and DCT-24 (c).

carbon atoms are reinforced to move to the nearby defects. After tempering process, a large amount of small carbides were produced in this way [25]. Collins and Dormer [11] and Yun et al. [26] reported that longer holding periods at cryogenic temperatures are essential for finer carbide precipitation. Different from the conversion of retained austenite to martensite, the for-
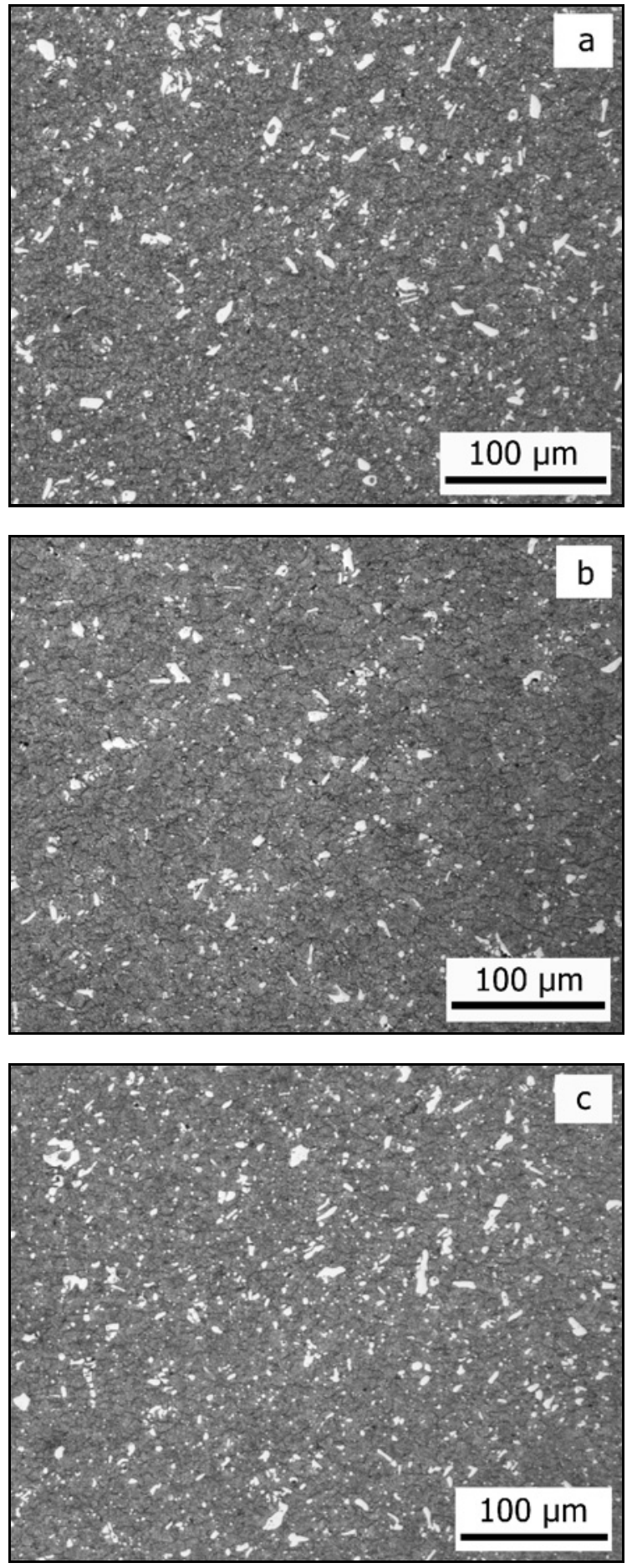

Fig. 4. The microstructure of samples in small-scale CHT (a), DCT-4 (b), and DCT-24 (c).

mation of fine carbides is a situation which depends on time. Longer durations at cryogenic temperature lead to the migration of much more carbon atoms to the defects and subsequently, number of small carbides increases. Nano-sized carbides occupy the microvoids and make the structure more dense and homogeneous. Therefore, this decreases the material strength very 

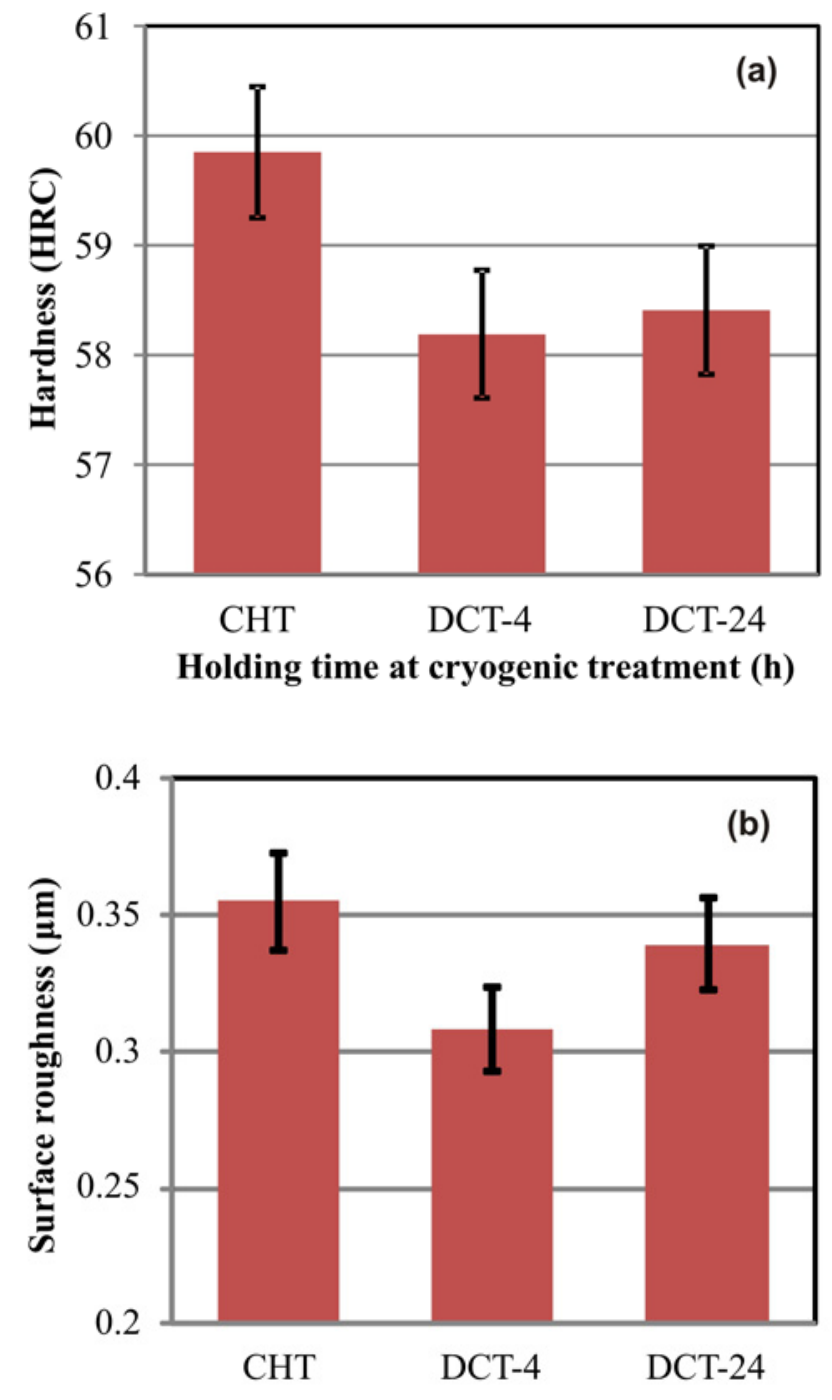

Holding time at cryogenic treatment (h)

Fig. 5. Macro hardness values (a) and average surface roughness values (b).

little but improves its toughness.

In Figs. $3 \mathrm{~b}$ and $4 \mathrm{~b}$, it is difficult to observe the difference in secondary carbide distribution for the DCT-4 sample in comparison to CHT sample. The increment in a number of overall carbides can be observed considerably for the DCT-24 sample. When Fig. 4c is compared with Figs. 4a,b, they agree with previous studies and number of secondary carbides increase with longer holding time in the cryogenic process. As a future study, Scanning Electron Microscope (SEM) examinations would give detailed information about the formation of secondary carbides.

\subsection{Hardness variation}

Hardness values were not significantly different from each other as seen in Fig. 5a. Volume fraction

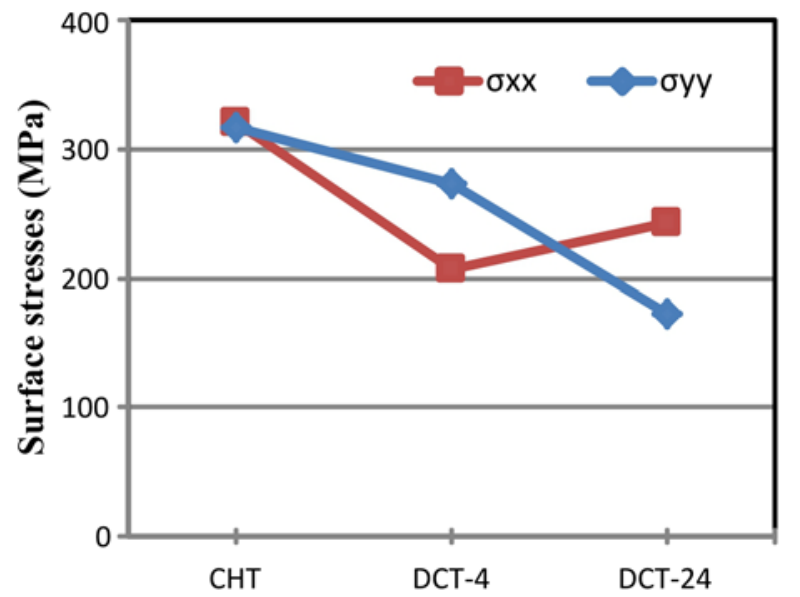

Fig. 6. Surface residual stresses by XRD in the axial $(x x)$ and tangential (yy) direction.

analysis of RA showed that almost all RA transformed to the martensite. RA content in the material creates undesirable effects because of its relatively soft and unstable structure and might be transformed during service conditions. Similar hardness values might be attributed to the high transformation rates of $\mathrm{RA}$ to martensite. The hardness of the sample CHT was found as 58.9 HRC. Marginal reductions of hardness values of samples DCT-24 and DCT-4 were 0.83 and $1.2 \%$, respectively.

\subsection{Surface roughness}

Surface finish is an important parameter affecting the performance and service life in the case of dynamic loading or working of mating parts. Surface finish is affected by the existence of the residual stresses and surface or subsurface microcracks [27]. Bensely et al. [28] stated that high carbide clustering led to improved wear resistance, dimensional stability and frictional properties. Tempering after DCT leads to a reduction in brittleness and thereby decrease stresses and sensitivity of microcracks. It is possible to state that DCT provides more dense and homogeneous structure because of very small carbide precipitation that results in the improved surface finish with high toughness and low residual stresses. According to Fig. 5b, DCT samples represented lower surface roughness values than sample CHT. Surface roughness value of sample CHT was $0.355 \mu \mathrm{m}$. The decrease in surface roughness values of samples DCT-24 and DCT-4 in comparison to CHT sample were 4.5 and $12 \%$, respectively.

\subsection{Residual stress}

According to residual stress measurements, residual surface stresses of samples CHT, DCT-4 and DCT-24 in axial direction were 321, 207 and $242 \mathrm{MPa}$, 
respectively. These results stated that cryogenic treatment reduced the stress values of the sample surfaces as seen in Fig. 6. Reductions in stress values for DCT-4 and DCT-24 in comparison to CHT were 35 and $24.6 \%$, respectively. Maximum stress reduction was observed for the surface of the DCT-4 sample in the axial direction. Although all surfaces had tensile residual stresses, compressive stress was observed in the subsurface of sample DCT-24 (Fig. 7a). Presence of compressive residual stresses for sample DCT-24 began at an approximate depth of $0.3 \mathrm{~mm}$. However, they did not form till $0.5 \mathrm{~mm}$ in depth for samples CHT and DCT-4.

Stresses in tangential direction decreased with prolonged holding times at cryogenic temperature and highest reduction arose for sample DCT-24. Stress values on the surfaces of CHT, DCT-4 and DCT-24 were found as $316.8,274.1$, and $172.5 \mathrm{MPa}$, respectively. When compared to sample $\mathrm{CHT}$, stress reductions for DCT-24 and DCT-4 were 45.5 and $13.47 \%$, respectively. Cryogenic treatment resulted that reduction in surface tensile stresses in tangential direction was identical to the axial direction (Fig. 6). While tensile residual stress for sample DCT-24 turned into compressive residual stress at an approximate depth of $0.4 \mathrm{~mm}$, tensile stresses of samples CHT and DCT-4 were kept on till $0.5 \mathrm{~mm}$ in depth as given in Fig. 7b.

Internal stresses occur when the thermal contractions take place inside the material during cryogenic treatment. Longer holding times at cryogenic temperature provide movement of more carbon atoms out of the crystal lattice and dissipation inside the material. The martensitic structure becomes supersaturated with the diffusion of carbon atoms inside the crystal defects. However, primary martensite is an undesirable structure because of its brittleness. Therefore, tempering process should be needed to relieve the residual stresses of the materials. Tempering also increases both the ductility and toughness and thereby provides dimensional stability of the material [29, 30]. Carbon atoms and alloying elements clustering come together to form carbides during tempering. As a result of this, carbide precipitation and the deficiency of martensite tetragonality led to relieve the internal stresses. Higher tensile stress relieving in sample DCT-24 might be attributed to the occurrence of more homogeneous carbide precipitation. However, it cannot be associated with RA, because all the samples include less than $2 \%$ RA.

\section{Discussion}

\subsection{Correlations of microstructure and hardness}

In literature, there are many studies about the re- lationship between hardness and cryogenic treatment. Molinari et al. [31] and Zhirafar et al. [32] suggested that cryogenic treatment led to negligible variation in hardness. Microstructure images of sample DCT-24 had more uniform precipitation and high number carbides in its microstructure. Moreover, almost all of the RA transformed into martensite for CHT, DCT-4 and DCT-24 samples. In addition to the transformation of RA, distribution of alloying elements and grain size are the factors affecting the hardness of the steel. It can be interpreted that low RA content affects the hardness in the same manner and consequently hardness values were found to be very close to each other. Hence, slight differences in hardness after cryogenic treatment can be accepted marginally. Despite DCT does not make any significant effect on the hardness, improvement in toughness and wear resistance is one of the most desirable effects of DCT [32]. At the same time, the favoured hardness values (54-62 HRC) for service conditions remained in the required range. Tempering process might reduce the amount of RA. However, tempering applied to samples after the cryogenic treatment is a more effective step to obtain preferable mechanical changes which result in high strength, wear resistance, dense and homogeneous microstructure.

\subsection{Correlations of microstructure and residual stress}

Residual stresses in materials influence creep failure, fatigue and cracks caused by stress corrosion. Because tensile stress on subsurface accelerates the crack propagation, compressive stress on subsurface is essential in this respect. The reduction in stresses decreases the risk of brittleness and crack formation over the surface. More carbide distribution and diminishing of martensite tetragonality aid to reduce the residual stresses. After short and long holding times at cryogenic temperature, uniform and fine distribution of carbides occurred for the DCT-24 sample. DCT-4 and DCT-24 samples had lower surface tensile stresses than CHT. Moreover, these stresses turned into compressive stresses at the subsurface of the DCT-24 sample. Compressive residual stresses occurred in the sub (surface) layers of materials restricting the formation and propagation of fatigue cracks and considerably improved wear properties [33]. In this respect, transformation into compressive stress is a more desirable condition and thereby improves the tool life.

\subsection{Correlations of microstructure and surface roughness}

For stamping and punching applications, tools and workpieces have high contact loads that lead to high contact pressures, temperatures, wear, fatigue and 
E. Demir, İ. Toktaş / Kovove Mater. 562018 153-161
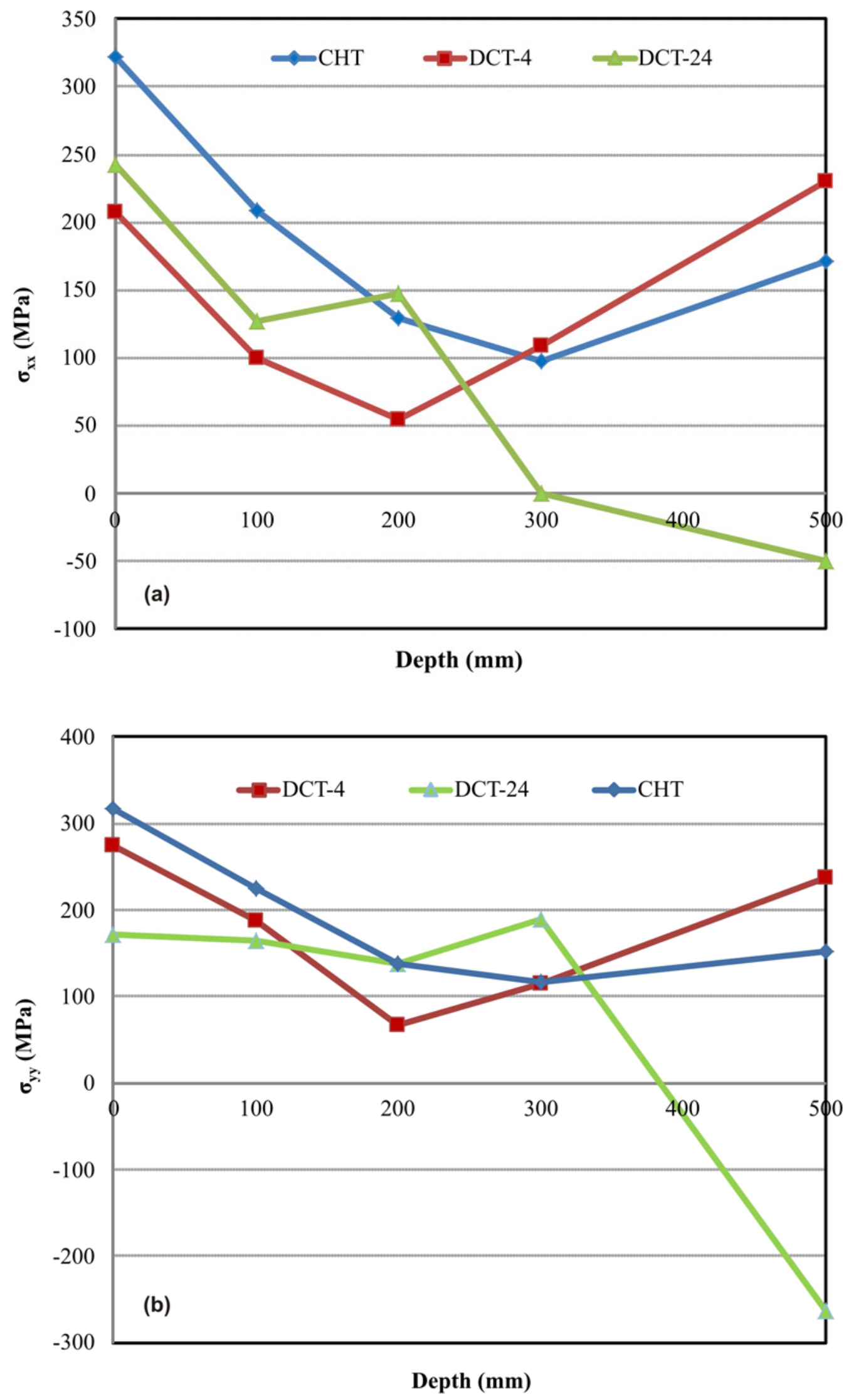

Fig. 7. Surface and subsurface residual stresses in the axial direction (a) and tangential direction (b). 
chipping. Surface properties of the tool materials are affected by the residual stresses and microcracks acting on materials surface or subsurface. Bensely et al. [19] examined the grinding effects on the case of carburized En 353 steel. They stated that microcracks could be observed in all the samples before tempering. Moreover, maximum reduction of microcracks occurred in DCT samples after tempering by means of fine carbide precipitation. Uniform distribution of fine carbides also diminishes the internal stresses of the martensite and decreases the sensitivity to microcracks [34]. Both higher carbide content and tougher matrix led to improving the surface roughness. Both of the cryo-treated samples represented lower surface roughness values in comparison to CHT. Reduction in surface roughness might be attributed to the uniform and more carbide distribution.

\section{Conclusions}

Cryogenic treatment decreased the tensile stress on AISI D2 steel surface in comparison to CHT and converted tensile stress into compressive stress on the DCT-24 subsurface. Also, lowest residual stress was obtained for sample DCT-24. Surface roughness values went down. The results obtained from the tests demonstrated that surface roughness values of sample CHT were higher and DCT-4 sample had the lowest surface roughness value. The microstructure of sample DCT-24 had significantly more uniform and dense carbide distribution in comparison to CHT sample. Differences in hardness and RA contents are considered marginal among all the samples. As a result, it is revealed that cryogenic treatment is an effective method to reduce residual stresses by means of finer and homogeneous carbide precipitation.

\section{References}

[1] Senthilkumar, D., Rajendran, I., Pellizzari, M., Siiriainen, J.: Journal of Materials Processing Technology, 211, 2011, p. 396 doi:10.1016/j.jmatprotec.2010.10.018

[2] Das, D., Dutta, A. K., Ray, K. K.: Wear, 266, 2009, p. 297. doi:10.1016/j.wear.2008.07.001

[3] Thornton, R., Slatter, T., Jones, A. H., Lewis, R.: Wear, 271, 2011, p. 2386. doi:10.1016/j.wear.2010.12.014

[4] Thelning, K. E.: Steel and its Heat Treatment. London, Butterworths 1984.

[5] Roberts, G., Krauss, G., Kennedy, R.: Tool Steels. Metals Park, ASM International 1998.

[6] Das, D., Ray, K. K., Dutta, A. K.: Wear, 267, 2009, p. 1361. doi:10.1016/j.wear.2008.11.029

[7] Alexandra, I., Bulancea, V.: Member/Customer Service Center. Materials Park, ASM International 2002.
[8] Huang, J. Y., Zhu, Y. T., Liao, X. Z., Beyerlein, I. J., Bourke, M. A., Mitchell, T. E.: Materials Science and Engineering A, 339, 2003, p. 241. doi:10.1016/S0921-5093(02)00165-X

[9] Tyshchenko, A. I., Theisen, W., Oppenkowski, A., Siebert, S., Razumov, O. N., Skoblik, A. P., Gavriljuk, V. G.: Materials Science and Engineering A, 527, 2010, p. 7027. doi:10.1016/j.msea.2010.07.056

[10] Akhbarizadeh, A., Javadpour, S.: Materials Letters, 93, 2013, p. 247. doi:10.1016/j.matlet.2012.11.081

[11] Collins, D. N., Dormer, J.: Heat Treatment Met., 3, 1997, p. 71

[12] Surberg, C. H., Stratton, P., Lingenhöle, K.: Cryogenics, 48, 2008, p. 42. doi:10.1016/j.cryogenics.2007.10.002

[13] Rhyim, Y. M., Han, S. H., Na, Y. S., Lee, J. H.: Solid State Phenomena, 118, 2006, p. 9. doi:10.4028/www.scientific.net/SSP.118.9

[14] Das, D., Dutta, A. K., Ray, K. K.: Wear, 267, 2009, p. 1371. doi:10.1016/j.wear.2008.12.051

[15] Das, D., Ray, K. K.: Materials Science and Engineering, 541, 2012, p. 45. doi:10.1016/j.msea.2012.01.130

[16] Das, D., Ray, K. K.: Philosophical Magazine Letters, 92, 2012, p. 295. doi:10.1080/09500839.2012.669052

[17] Das, D., Dutta, A. K., Ray, K. K.: Materials Science and Engineering, 527, 2010, p. 2194. doi:10.1016/j.msea.2009.10.071

[18] Oppenkowski, A., Weber, S., Theisen, W.: Journal of Materials Processing Technology, 210, 2010, p. 1949. doi:10.1016/j.jmatprotec.2010.07.007

[19] Bensely, A., Venkatesh, S., Lal, D. M., Nagarajan, G., Rajadurai, A., Junik, K.: Materials Science and Engineering A, 479, 2008, p. 229. doi:10.1016/j.msea.2007.07.035

[20] Paydar, H., Amini, K., Akhbarizadeh, A.: Kovove Mater., 52, 2014, p. 163. doi:10.4149/km_2014_3_163

[21] Amini, K., Akhbarizadeh, A., Javadpour, S.: Kovove Mater., 54, 2016, p. 331. doi:10.4149/km_2016_5_331

[22] Xu, L. Y., Zhu, J., Jing, H. Y., Zhao, L., Lv, X. Q., Han, Y. D.: Materials Science and Engineering A, 673, 2016, p. 503. doi:10.1016/j.msea.2016.07.101

[23] Steinzig, M., Ponslet, E.: Experimental Techniques, 27, 2003, p. 43. doi:10.1111/j.1747-1567.2003.tb00114.x

[24] Das, D., Dutta, A. K., Ray, K. K.: Philosophical Magazine, 89, 2009, p. 55. doi:10.1080/14786430802534552

[25] Liu, H. H., Wang, J., Shen, B. L., Yang, H. S., Gao, S. J., Huang, S. J.: Materials \& Design, 28, 2007, p. 1059. doi:10.1016/j.matdes.2005.09.007

[26] Dong, Y., Lin, X. P., Xiao, H. S.: Heat Treatment of Metal, 3, 1998, p. 55.

[27] Paul, S., Dhar, N. R., Chattopadhyay, A. B.: Journal of Materials Processing Technology, 116, 2001, p. 44. doi:10.1016/S0924-0136(01)00839-1

[28] Bensely, A., Prabhakaran, A., Lal, D. M., Nagarajan, G.: Cryogenics, 45, 2005, p. 747. doi:10.1016/i.cryogenics.2005.10.004

[29] Avner, S. H.: Introduction to Physical Metallurgy. New Delhi, Tata McGraw-Hill Publishing Co. Ltd. 2003.

[30] Vanvlack, L. H.: Elements of Material Science and Engineering. Boston, Addison-Wesley 1998.

[31] Molinari, A., Pellizzari, M., Gialanella, S., Straffelini, 
G., Stiasny, K. H.: Journal of Materials Processing Technology, 118, 2001, p. 350. doi:10.1016/S0924-0136(01)00973-6

[32] Zhirafar, S., Rezaeian, A., Pugh, M.: Journal of Materials Processing Technology, 186, 2007, p. 298. $\underline{\text { doi:10.1016/j.jmatprotec.2006.12.046 }}$
[33] Rossini, N. S., Dassisti, M., Benyounis, K. Y., Olabi, A. G.: Materials Design, 35, 2012, p. 572. doi:10.1016/j.matdes.2011.08.022

[34] Çiçek, A., Kara, F., Kivak, T., Ekici, E., Uygur, I.: Journal of Materials Engineering and Performance, 24, 2015, p. 4431. doi:10.1007/s11665-015-1712-x 